\title{
MACROSCOPIC STUDY OF CELIAC, CRANIAL MESENTERIC AND CAUDAL MESENTERIC ARTERIES IN THE EUROPEAN HARE
}

\author{
Flešárová, S., Maženský, D. \\ Department of Anatomy, Histology and Physiology \\ University of Veterinary Medicine and Pharmacy, Komenského 73, 04181 Košice
}

Slovakia

slavka.flesarova@uvlf.sk

\section{ABSTRACT}

The aim of this paper was to describe the branching schema of the ventral branches of the abdominal aorta: the $a$. celiaca, the $a$. mesenterica cranialis and the a. mesenterica caudalis. The study was carried out on nine adult European hares using the corrosion cast technique. After the euthanasia, the vascular network was perfused with saline. Batson's corrosion casting kit No. 17 was used as a casting medium. After polymerisation of the medium, the maceration was carried out in $\mathrm{KOH}$ solution. In all specimens, the first branch originating from the $a$. celiaca was the $a$. lienalis. The a. hepatica was present as the second branch in four cases and as the third branch also in four cases. The first branch of the a. mesenterica cranialis was the a. colica media in seven cases. The second branch was represented by the $a$. pancreaticoduodenalis caudalis also in seven cases. Two aa. jejunales originated as the third branch. In seven cases, the fourth branch formed the truncus jejunalis and the fifth branch the a. ileocecalis. The $a$. mesenterica caudalis had a uniform arrangement in all of the specimens. The results enabled us to conclude that there was higher variability of the branching pattern of the $a$. celiaca in comparison with the $a$. mesenterica cranialis and the a. mesenterica caudalis in the European hare.

Key words: a. celiaca; a. mesenterica caudalis; anatomical study; a. mesenterica cranialis; European hare

\section{INTRODUCTION}

Anatomical studies dealing with blood vessels supplying the visceral organs of the abdominal cavity are very important. They help to better understand the arrangement of the principal intraabdominal arteries, their variations and anomalies and to avoid the obstruction of blood vessels in different clinical and pathological conditions as well as in surgical procedures [12].

A detailed knowledge of the variations in the arterial system of the visceral organs inside the abdominal cavity is essential in surgical and radiological anatomy. The high possibility of gastrointestinal disturbances caused by differ- 
ent pathological agents requiring rapid diagnosis and surgical intervention, makes the knowledge of vascular variations an especially important factor [11].

The anatomical pattern of the branches arising from the ventral surface of the abdominal aorta in the domesticated rabbit have been described in detail in many different studies $[1,2,4,5,6,7,8,10,12]$. Despite the high occurrence of the European hare as a wild animal in Europe, the detailed knowledge of its arterial system is still lacking in the literature.

The aim of our study was to describe the arrangement and distribution of the branches originating from, the a.celiaca, the a.mesenterica cranialis and the a.mesenterica caudalis in the European hare.

\section{MATERIALS AND METHODS}

This study was carried out on 9 adult European hares (Lepus Europaeus, L. 1758, age 140 days). We used hares (obtained from ISFA APRC, Nitra, Slovak Republic) of both sexes (female $\mathrm{n}=5$; male $\mathrm{n}=4$ ) weighing between $2.5-3.2 \mathrm{~kg}$ in an accredited experimental laboratory of the University of Veterinary Medicine and Pharmacy in Košice, Slovakia. The animals were kept in cages under standard conditions (temperature $15-20^{\circ} \mathrm{C}$, relative humidity $45 \%$, 12-hour light period), and fed with a granular feed mixture (O-10 NORM TYP, Spišské kŕmne zmesi, Spišské Vlachy, Slovakia). The drinking water was available to all animals ad libitum. Thirty minutes before sacrifice by intravenous administered of embutramide (T-61, $\left.0.3 \mathrm{ml} . \mathrm{kg}^{-1}\right)$, the animals were injected intravenously with heparin $\left(50000 \mathrm{IU} \cdot \mathrm{kg}^{-1}\right)$. Immediately after euthanasia, the vascular network was perfused with a physiological solution. During manual injection through the ascending aorta, the right heart atrium was opened in order to lower the pressure in the vessels which enabled an optimal injection distribution. $50 \mathrm{ml}$ of Batson's corrosion casting kit No. 17 (Dione, České Budějovice, Czechia) was used as the casting medium. The maceration was carried out in $2-4 \%$ $\mathrm{KOH}$ solution for a period of 5 days at $60-70^{\circ} \mathrm{C}$. The study was carried out under the authority decision No. 2647/07$221 / 5$.

\section{RESULTS}

The a. celiaca, the first unpaired artery from the ventral surface of the abdominal aorta is intended for the blood supply to the spleen, stomach, liver, pancreas, omentum and partly the duodenum. It was directed to the left and caudolaterally.

The a. celiaca gave off three branches in six cases and four branches in three cases (Fig. 1). In all of the cases, the first branch arising from the $a$. celiaca was the $a$. lienalis (Fig. 1). The second branch was represented by the $a$. hepatica in four cases, by the a. gastrica sinistra in two cases, by a common trunk for the a. gastrica dextra and the a. gastrica sinistra in two cases and by the a. gastrica dextra in one case (Fig. 1). The a. hepatica was the third branch in four cases, a common trunk for the a. gastrica dextra and the a. gastrica sinistra in three cases, the a. gastrica dextra in one case and the a. gastrica sinistra also in one case (Fig. 1). A doubled a. gastrica dextra was present in one case as the fourth branch. Also, in one case was found as the fourth branch: the a. hepatica (Fig. 1) and the a. gastrica sinistra.

In four cases, the $a$. lienalis gave off the $r$. gastricus dexter as the first branch. In one case, the r. gastricus dexter originated directly from the lateral surface of the aorta $a b$ dominalis cranially to the origin of the $a$. celiaca. The spleen was supplied by small branches arising from the a. lienalis; two branches in three cases, three in four cases and four in two cases. The aa. gastricae breves had an opposite direction to the previous branches. They participated on supplying blood to the gastric wall in number of one in one case, of two in four cases, of three in three cases and in number of four in one case. The main continuation of $a$. lienalis was the a. gastroepiploica sinistra running along the greater curvature of stomach and anastomosing with the a. gastroepiploica dextra from the opposite direction. The a. gastrica sinistra supplied the wall of the stomach by small branches which consisted of two branches in one case, three in two cases, four in four cases and five in two cases. The number of small gastric branches arising from the a. gastrica dextra was three branches in three cases, two and five in two cases, and four in one case. In the case of the presence of the doubled a. gastrica dextra, each of them gave off two branches to the wall of the stomach. In two cases, the a. hepatica sent as the first branch, the a. gastrica dextra. After the origin of this artery, the a. hepatica entered the liver through the porta hepatis. Its continuation was represented by the 


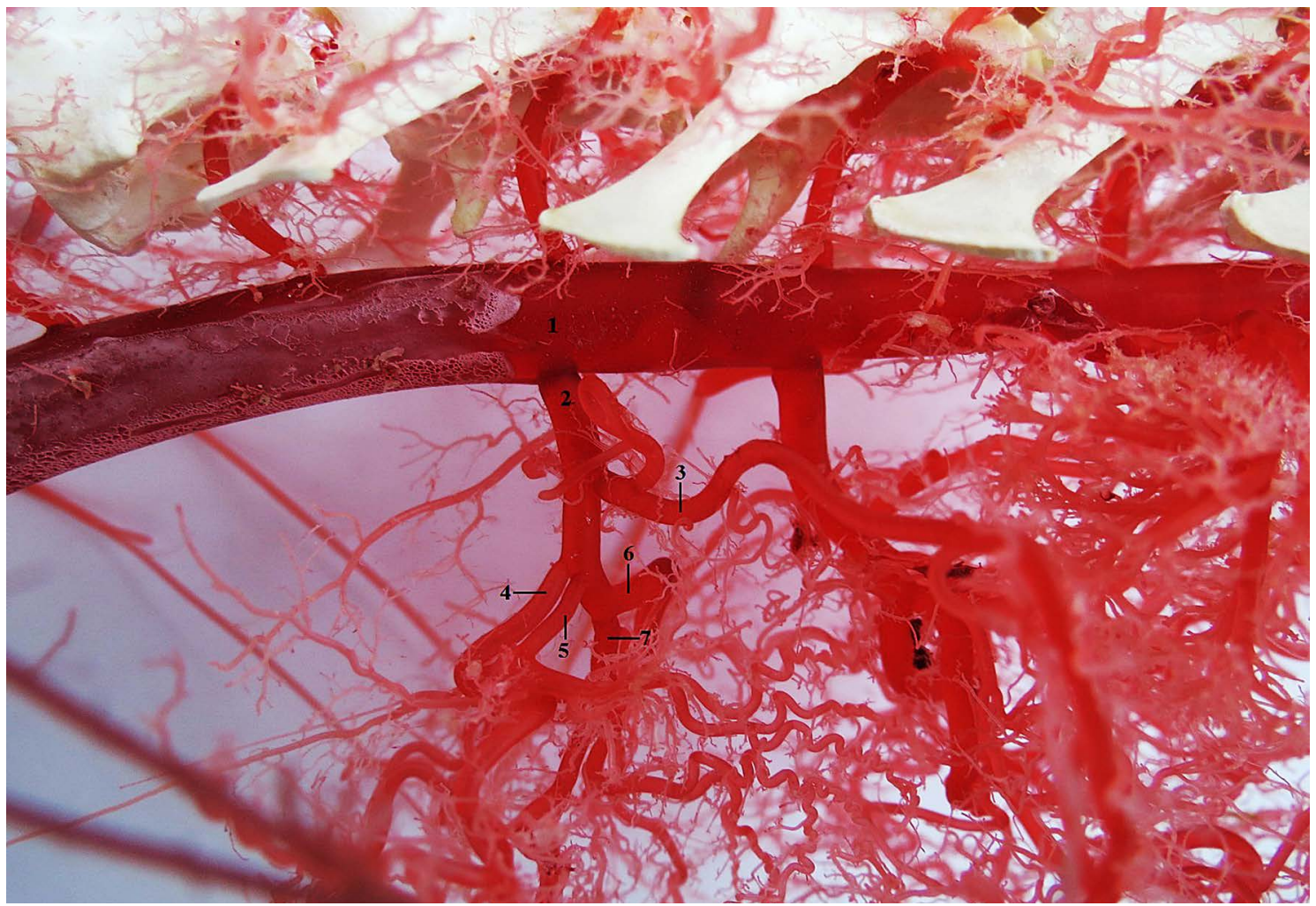

Fig. 1. Branching pattern of the $a$. celiaca

1 - aorta abdominalis; 2 - a. celiaca; 3 - a. lienalis; 4 - a. gastrica dextra; 5 - a. gastrica sinistra 6 - a. hepatica; 7 - a. gastroduodenalis. Macroscopic image, lateral view

a. gastroduodenalis which was divided terminally into the a. gastroepiploica dextra and the a. pancreaticoduodenalis cranialis. In the rest of the cases, the a. hepatica ultimately divided into only two branches: the a. gastroepiploica dextra and the $a$. pancreaticoduodenalis cranialis.

The $a$. mesenterica cranialis which supplied the pancreas, small intestine, cecum, ascending colon and transverse colon, had five branches in seven cases (Fig. 2) and six branches in two cases. The first branch was represented by the a colica media in seven cases (Fig. 2) and by the a. pancreaticoduodenalis caudalis in two cases. The $a$. colica media originated as the second branch in two cases and the a. pancreaticoduodenalis caudalis in seven cases (Fig. 2). The aa. jejunales originated as the third branch in different numbers: one in one case (Fig. 2), two in five cases, three in two cases and four in one case. The fourth branch was formed in one case by a single $a$. colica dextra and also in one case by a doubled a. colica dextra. In seven cases, the fourth branch was the truncus jejunalis which gave off the aa. jejunales (Fig. 2). They appeared as ten branches in one case, twelve in two cases and thirteen in four cases. The truncus jejunalis constituted the fifth branch in two cases with ten and thirteen aa. jejunales. In seven cases, the fifth branch was represented by the $a$. ileocolica which gave off: a. cecalis dorsalis, a. cecalis ventralis, a. appendicularis, and a single $a$. colica dextra in two cases or doubled $a$. colica dextra in five cases (Fig. 2). The sixth branch was formed by the $a$. ileocolica with branches: $a$. cecalis dorsalis, a. cecalis ventralis, a. appendicularis and doubled a. colica dextra.

The $a$. mesenterica caudalis as the latest unpaired and ventrally originating branch from aorta abdominalis was in all cases divided into two branches. It supplied the descending colon and rectum. The cranially directed $a$. colica sinistra was smaller in diameter than the stouter and caudally directed $a$. rectalis cranialis. The above described arrangement was found in all of the cases (Fig. 3).

\section{DISCUSSION}

The domesticated rabbit is one of the species most frequently used in the study of various diseases associated 


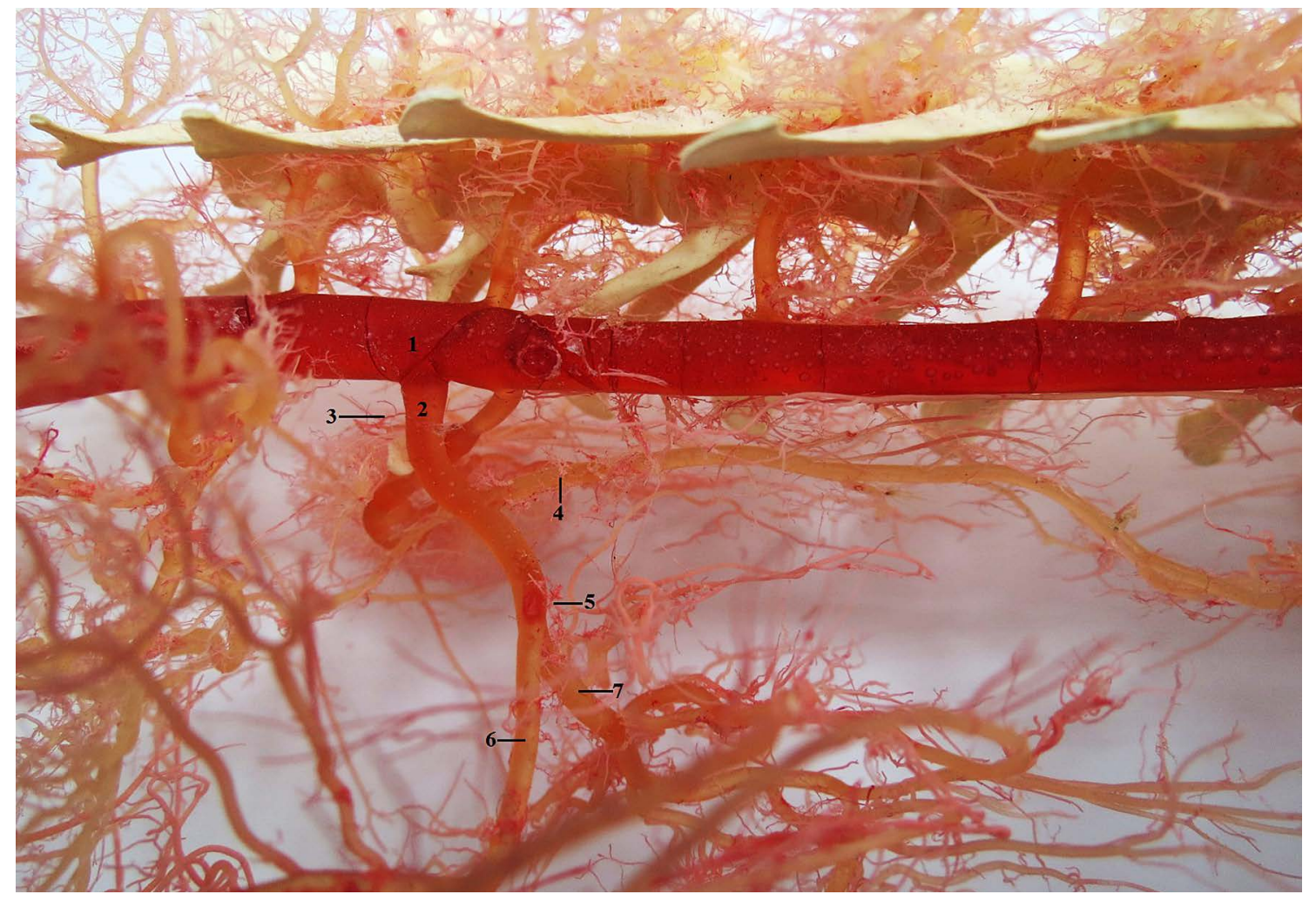

Fig. 2. A. mesenterica cranialis and its main branches

1 - aorta abdominalis; 2 - a. mesenterica cranialis; 3 - a. colica media; 4 - a. pancreaticoduodenalis caudalis 5 - a. jejunalis; 6 - truncus jejunalis; 7 - a. ileocecalis. Macroscopic image, lateral view

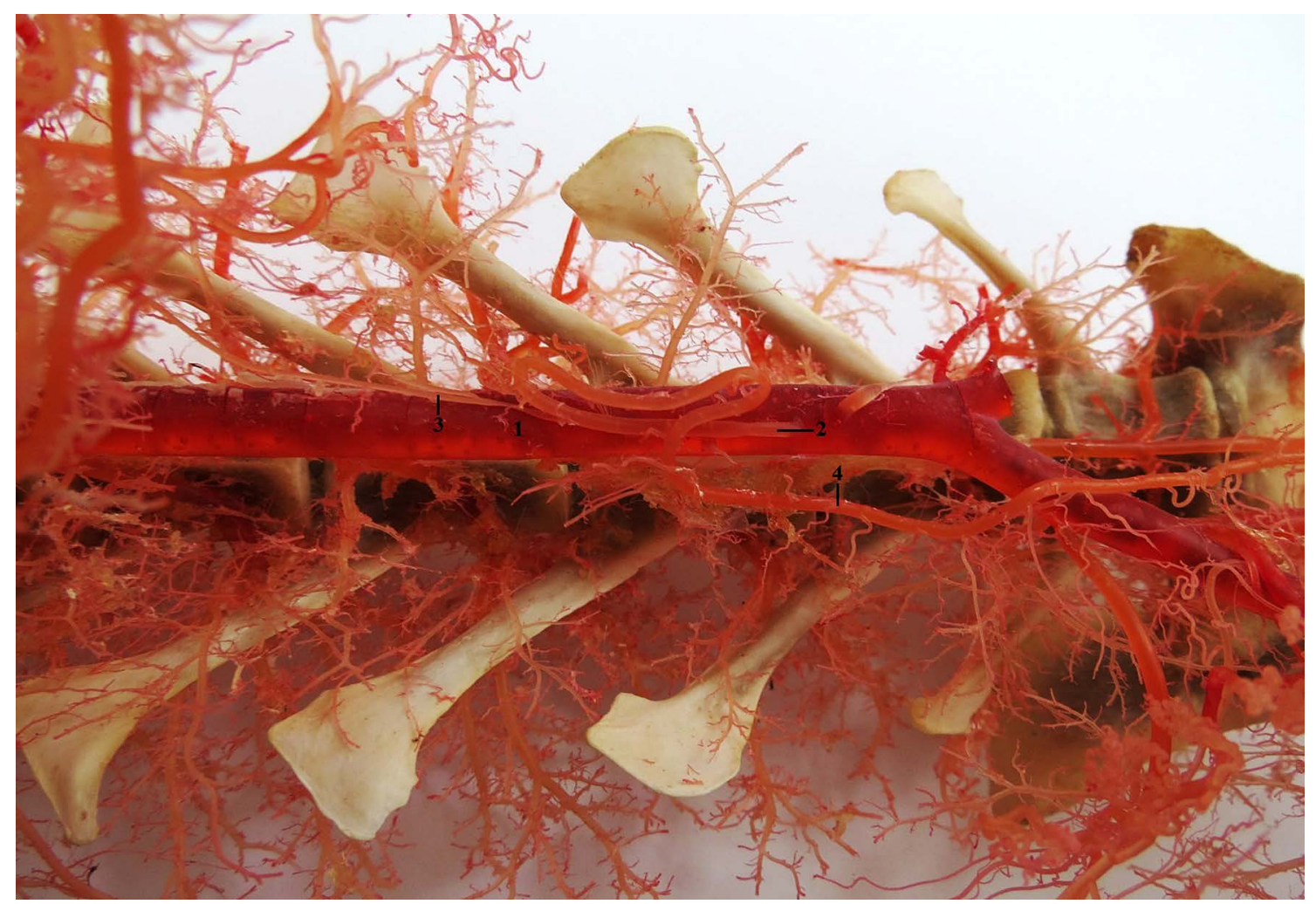

Fig. 3. Arrangement of the a. mesenterica caudalis

1 - aorta abdominalis; 2 - a. mesenterica caudalis; 3 - a. colica sinistra $4-a$. rectalis cranialis Macroscopic image, ventral view 
with the gastrointestinal tract as well as in the study of pharmacology, toxicology and surgery [12]. For this reason, the arterial system of its abdominal viscera has been described more in detail $[1,2,5,7,8]$. The studies dealing with the variations of the arterial system in the wild European hare are much rarer $[3,9]$.

In the study of the arterial system of the New Zealand white rabbit, a uniform division of the $a$. celiaca into two trunks was described. The first trunk was common for the a. hepatica, the a. gastroduodenalis and the a. gastrica dextra. The second trunk was divided into the $a$. lienalis and the a. gastrica sinistra [10]. A bi d u - Figu eir e do et al. [1] described in the domesticated rabbit as the first branch in all cases, the $a$. lienalis, which is consistent with our findings. The $a$. hepatica as the first branch of the a. celiaca was designated by $\mathrm{P}$ o p e s k o et al. [10]. The $a$. lienalis of the domesticated rabbits sends one to five branches to the spleen [1], while in the European hare two to four branches to the spleen. In the hare, we found one to four aa. gastricae breves, but in the domesticated rabbit there were one to five [1]. In the hare and rabbit, the number of small branches with origins from the a. gastrica sinistra and supplying the wall of the stomach was the same [1]; except in the rabbit, these small branches originated off of the a. gastroduodenalis and the a. hepatica [1]. In the hare, the a. gastrica sinistra was intended only for the lesser curvature of the stomach.

The a. pancreaticoduodenalis caudalis, as the first branch originating from the $a$. mesenterica cranialis in the rabbit, was found in all cases $[2,12]$ or in more than one half of the cases $[5,8]$. In $6.7 \%$ of the cases, the $a$. pancreaticoduodenalis caudalis was duplicated [8]. A single or doubled $a$. pancreaticoduodenalis caudalis was described by $\mathrm{K} \mathrm{ig}$ a $\mathrm{t}$ a et al. [7]. In the hare, we found the $a$. pancreaticoduodenalis caudalis as the first branch in two cases. In the hare, the $a$. colica media originated as the second branch in two cases. In the rabbit, the a. colica media represented the second branch in all cases [2, 12], in more than one half of cases [5], or it formed the first branch [8]. Kig a ta et al. [7] found one to three $a$. colica media in the rabbit. In $80 \%$ of the male and $86.67 \%$ of female rabbits, one single a. jejunalis was the third branch [5]. In the hare, there were one to four $a$. jejunalis originating from the a. mesenterica cranialis before its terminal division. In the hare, the fourth branch was formed in one case by a single a. colica dextra, in one case by a doubled $a$. colica dextra and in seven cases by the truncus jejunalis. The terminal division of the $a$. mes- enterica cranialis into the truncus jejunalis and the $a$. ileocolica in the rabbit was in the literature more common [2, $8,12]$ and was the same as in the hare. In the rabbit, from the truncus jejunalis originated the aa. jejunales in different numbers: 18-20 [12], 17-18 [5], 11-23 [8] and 11-17 [7]. One to six aa. jejunales arose directly from the $a$. mesenterica cranialis [8]. In the hare, the aa. jejunales originating from the truncus jejunalis were present in number from 10 to 13 . The division of the a. ileocolica from which originated branches supplying the ileum, cecum, appendix and proximal colon was very variable in the hare and the rabbit $[5,7,8,12]$.

In the hare and rabbit, the arrangement of the $a$. mesenterica caudalis showed the same schema: a slenderer $a$. colica sinistra in the cranial direction and a stouter $a$. rectalis cranialis in the caudal direction $[1,5,12]$.

\section{CONCLUSIONS}

There was a higher variability of the branching pattern of the $a$. celiaca in comparison with the a. mesenterica cranialis and the $a$. mesenterica caudalis in the European hare. The distribution patterns of the $a$. celiaca and the $a$. mesenterica cranialis in the hare are highly specialized in this species. Such specialization should always be considered when performing abdominal surgery.

\section{REFERENCES}

1. Abidu-Figueiredo, M., Xavier-Silva, B., Cardinot, T.M., Babinski, M. A., Chagas, M.A., 2008: Celiac artery in New Zealand rabbit: Anatomical study of its origin and arrangement for experimental research and surgical practice. Pesq. Vet. Bras., 28, 237-240.

2. Ahasan, A.S.M.L., Islam, M.S., Kabria, A.S.M.G., Rahman, M. L., Hassan, M. M., Uddin M., 2012: Major variation in branches of the abdominal aorta in New Zealand White rabbit (Oryctolagus Cuniculus). Intern. J. Nat. Sci., 2, 91-98.

3. Brudnicki, W., Kirkillo-Stacewicz, K., Skoczylas, B., Nowicki, W., Jablonski, R., Brudnicki, A., Wach, J., 2015: The arteries of the brain in hare (Lepus europaeus Pallas, 1778). Anat. Rec., 298, 1774-1779.

4. Craigie, E. H., 1948: Bensley's Practical Anatomy of the Rabbit. Blakiston Company, Philadelphia, 325-326. 
5. Estruc, T. M., Nascimento, R. M., Siston, N. M., Mencalha, R., Abidu-Figueiredo, M., 2015: Origin and main branches of the cranial and caudal mesenteric arteries in the New Zealand rabbit. J. Morphol. Sci., 32, 143-148.

6. Jeican, I. I., Gheban, D., Socaciu, M., Toader, S., Ciuce, C., 2016: Experimental model of mixed intestinal infarction in rabbit. Rev. Med. Chir. Soc. Med. Nat. Iasi, 120, 592-603.

7. Kigata, T., Ikegami, R., Shibata, H., 2017: Macroscopic anatomical study of the distribution of the cranial mesenteric artery to the intestine in the rabbit. Anat. Sci. Int., 93, 291-298.

8. Malinovský, L., Bednárová, Z., 1990: Variability of ramification of the $a$. mesenterica cranialis in the domestic rabbit (Oryctolagus cuniculus $f$. domestica). Folia Morphol., 38, 283-292.

9. Mazensky, D., Flesarova, S., 2015: The arterial blood supply to the cervical spinal cord in European hare. Biologia, 70, $406-410$.
10. Popesko, P., Rajtova, V., Horak, J., 1990: Anatomic Atlas of Small Laboratory Animals I. 1st edn., Príroda, Bratislava, 67-78.

11. Šulla, I., Lukáč, I., 2010: Ischemic Damage of Spinal Cord in Experiment (In Slovak). P. J. Šafárik University Press, Košice, $125 \mathrm{pp}$.

12. Uddin, M., Rahman, M. L., Alim, M. A., Ahasan, A.S. M.L., 2012: Anatomical study on origin, course and distribution of cranial and caudal mesenteric arteries in the White New Zealand rabbit (Oryctolagus cuniculus). Intern. J. Nat. Sci., 2, $54-59$. 